\title{
MDR1-targeted siRNA delivery with cationic dendritic conjugated polymers
}

\author{
FENG XuLi, LÜ FengTing, LIU LiBing* \& WANG Shu* \\ Key Laboratory of Organic Solids, Institute of Chemistry, Chinese Academy of Sciences, Beijing 100190, China
}

Received March 5, 2013; accepted April 11, 2013; published online June 6, 2013

\begin{abstract}
A cationic dendritic polyfluorene (PFP) is examined as a siRNA delivery vector. This material was designed to facilitate the nucleic acid binding, encapsulation and efficient cellular uptake. PFP can effectively protect siRNA against nuclease degradation, which is necessary for gene carriers. PFP can be used for multidrug resistance gene-targeted siRNA delivery in doxorubicin (Dox)-resistant human breast cancer cells (MCF7) cells. As a siRNA transfection agent, PFP can efficiently achieve the reversal of drug resistance and enhance the drug sensitivity. These new features and capabilities represent a major step toward conjugated polymers that can function for therapeutic application.
\end{abstract}

conjugated polymers, siRNA, delivery, multidrug resistance, therapeutic

Citation: Feng X L, Lü F T, Liu L B, et al. MDR1-targeted siRNA delivery with cationic dendritic conjugated polymers. Chin Sci Bull, 2013, 58: 2762-2766, doi: $10.1007 / \mathrm{s} 11434-013-5899-7$

Breast carcinoma has become the main killer among women worldwide [1]. Particularly, multidrug resistance (MDR) has been a major obstacle to the successful chemotherapy of progressive breast cancer [2]. The overexpression of $M D R I$ gene and its product, P-glycoprotein (P-gp), is the major mechanism causing the drug resistance. P-gp acts as an energy-dependent drug efflux pump to extrude chemotherapeutic drugs such as doxorubicin (Dox) from cell cytoplasm to outside of plasma membrane [3], leading to reduced intracellular effective drug concentration and augmenting cell survival. A lot of research has done to reverse MDR, for example, several compounds which can inhibit the efflux activity of drug transporters have been fully investigated for sensitizing cancer cells to chemotherapy, but their clinical application is still limited because of serious side effects $[4,5]$. Therefore, new strategies which can down-regulating the drug resistance should be developed.

Gene-based therapies hold great potential in pharmaceutical research [6,7]. Specially, small interfering RNAs (siRNA) are widely employed to achieve effective gene regulation [8,9]. Despite the considerable potential of

*Corresponding authors (email: liulibing @iccas.ac.cn; wangshu@iccas.ac.cn)
siRNA for treating cancers, it is generally recognized that the main obstacle to the use of siRNA therapeutics is inadequate delivery and transfection. The cellular uptake of naked siRNA would be very low because of the molecules' negative charge renders them poor membrane permeability. In addition, the rapid degradation of nucleic acids, particularly siRNA by serum nucleases is really a big problem that further aggravates the need for a protective carrier [10]. Many promising strategies have been developed for plasmid DNA (pDNA) and siRNA delivery. Recombinant viruses are proved to be effective transfection vectors, however, serious problems of immunogenicity, carcinogenicity and inflammation hinder their further clinical application [11]. Thus the development of nonviral vectors is of particular important in recent years, such as cationic polymers and lipids. However, their delivery efficiency remains low [12]. Therefore, developing new safe and efficient transfection agents is still required.

Very recently, conjugated polymers have been demonstrated for sensing and biomedical applications because of their high fluorescence brightness, good photostability, and lower toxicity [13-22]. We have developed an intrinsically fluorescent cationic polyfluorene [23] (PFP, see its chemcial 
structure in Scheme 1) for delivery and transfection of plasmid DNA with $92 \%$ efficiency, which surpasses that of commercial transfection agents, lipofectamine 2000 (Lipo) and polyethylenimine (PEI). Except for simultaneous imaging and highly efficient transfection of plasmid DNA, in this work, we show that the PFP can also be used for efficient MDR1-targeted siRNA delivery in doxorubicin-resistant MCF7/ADR cells. The results showed that we can efficiently achieve the reversal of drug resistance and enhance the drug sensitivity with PFP as siRNA transfection agent.

\section{Experimental}

\subsection{Materials and measurements}

The PFP was synthesized by our previous method [23]. The water was purified using a Millipore filtration system. Methylthiazolyldiphenyl-tetrazolium bromide (MTT) was obtained from Xinjingke Biotechnology Co., Ltd (Beijing, China). Goldview DNA dye was purchased from Beijing SBS Genetech Co. Ltd (Beijing, China). Lipofectamine ${ }^{\mathrm{TM}}$ 2000 was purchased from Invitrogen (Carlsbad, USA). TRIzol reagent and DEPC (diethylprocarbonate) water were purchased from Beyotime Institute of Biotechnology (Shanghai, China). MCF7/ADR cells were purchased from KeyGEN Biotech (Nanjing, China). Zeta potentials and size analysis were measured on a Nano ZS (ZEN3600) system. PCR was conducted on a Bio-Rad Mycycler Thermocycler. The image of the gel was taken by a Bio-Rad Molecular Imager ChemiDox XRS system. The absorbance for MTT analysis was recorded on a microplate reader (BIO-TEK Synergy HT, USA) at a wavelength of $520 \mathrm{~nm}$.

\subsection{SiRNA and cells}

The siRNA were manufactured by Shanghai GeneChem Co., Ltd. and designed to target the human MDRI mRNA [24] at

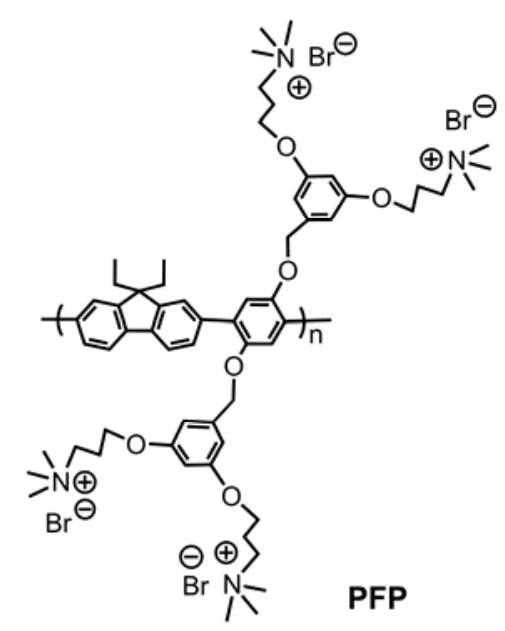

Scheme 1 Chemical structure of cationic dendritic polyfluorene (PFP). the level of the region $88-108$ nt relative to the start codon (sense strand, 5'-GAAACCAACUGUCAGUGUATT-3', antisense strand, 5'-UACACUGACAGUUGGUUUCTT). The lyophilized siRNA were resuspended in $250 \mu \mathrm{L}$ GeneChem $1 \times$ universal buffer to give a $20 \mu \mathrm{mol} / \mathrm{L}$ stock solution. siRNA solutions were heated to $90^{\circ} \mathrm{C}$ for $2 \mathrm{~min}$ and then cooled down to room temperature, and stored under $4^{\circ} \mathrm{C}$ for further use. MCF7/ADR cells were grown in RPMI 1640 medium supplemented with $10 \%$ FBS, $50 \mathrm{U} / \mathrm{mL}$ penicillin, $50 \mathrm{mg} / \mathrm{mL}$ streptomycin in a $5 \% \mathrm{CO}_{2}$ atmosphere. In order to maintain the MDR phenotype, cell culture medium for the P-gp expressing MCF7/ADR cell line was supplemented with $1.0 \mu \mathrm{g} / \mathrm{mL}$ doxorubicin. MCF7/ADR cells were incubated in a doxorubicin-free medium for over 2 weeks before use for experimentation. All of cell lines were discarded after 3 months and new lines obtained from frozen stocks.

\subsection{Against nuclease degradation experiment}

Protection of siRNA against nuclease degradation by PFP was studied by gel electrophoresis assay. PFP/siRNA complex was incubated in $10 \% \mathrm{FBS}$ at $37^{\circ} \mathrm{C}$ for $6 \mathrm{~h}$. After $6 \mathrm{~h}$ incubation, $10 \times$ loading buffer was added to the samples and loaded onto the gel for electrophoresis assay.

\section{4 siRNA transfection}

MCF7/ADR cells $\left(3 \times 10^{5} /\right.$ well $)$ were plated in six-well plates $24 \mathrm{~h}$ prior to the experiment. The $12.5 \mu \mathrm{L}(20 \mu \mathrm{mol} / \mathrm{L})$ siRNA was diluted to $250 \mu \mathrm{L}$ with serum-free medium, and $2.5 \mu \mathrm{L}$ of PFP $(1.0 \mathrm{mmol} / \mathrm{L})$ was also diluted with $250 \mu \mathrm{L}$ serum-free media, then the diluted $250 \mu \mathrm{L}$ PFP was added to the $250 \mu \mathrm{L}$ diluted siRNA solution, mix gently and incubate for $15-20 \mathrm{~min}$ at room temperature. The $500 \mu \mathrm{L}$ of complexes were then added to a well containing cells and $700 \mu \mathrm{L}$ serum-free medium, mixing gently by rocking the plate back and forth. The $24 \mathrm{~h}$ after transfection, fresh supplemented RPMI $1640(1.0 \mathrm{~mL})$ without penicillin and streptomycin was added to the well. The $48 \mathrm{~h}$ after initial transfection, the medium was replaced with fresh supplemented RPMI 1640. The $72 \mathrm{~h}$ after initial transfection, the medium was removed and the cells were washed with phosphate buffered saline (PBS, $\mathrm{pH}$ 7.4) three times for RNA interference analysis.

\subsection{Reverse transcription-PCR}

After transfection for $72 \mathrm{~h}$, total cellular RNA was extracted from cells with TRIzol reagent and quantified by UV absorbance spectroscopy. The reverse transcription reaction was performed using the Quant First Strand cDNA Synthesis Kit (Tiangen Biotech) in a final volume of $20 \mu \mathrm{L}$ containing $2 \mu \mathrm{g}$ total RNA. After incubation at $37^{\circ} \mathrm{C}$ for $60 \mathrm{~min}$, the reverse transcription reaction was terminated. The newly 
synthesized cDNA was amplified by PCR. The $25 \mu \mathrm{L}$ reaction mixture contained $1 \mu \mathrm{L}$ cDNA as template, Primers used for MDRI amplification were: 5'-CCCATCATTGCAA-3' (sense) and 5'-GTTCAAACTTCTGCTCCTGA-3' (reverse). Primers for $\beta$-actin amplification were: 5'-ACCAACTGGGACGACATGGA-3' (sense) and 5'CTCCTTAATGTCACGCACGA-3' (reverse). Amplification cycles were: $95^{\circ} \mathrm{C}$ for $4 \mathrm{~min}$, the 30 cycles at $95^{\circ} \mathrm{C}$ for $30 \mathrm{~s}, 55^{\circ} \mathrm{C}$ for $30 \mathrm{~s}, 72^{\circ} \mathrm{C}$ for $2 \mathrm{~min}$; followed by $72^{\circ} \mathrm{C}$ for $5 \mathrm{~min}$. Amplification products were separated on $2 \%$ agarose gel stained with Goldview DNA dye (SBS Genetech). The fluorescence intensity of $\beta$-actin fragments served as the criteria for the MDR1 fragments.

\subsection{Rhodamine 123 efflux assay}

After transfection for $72 \mathrm{~h}$, all cells were trypsinized and resuspended in $1 \mathrm{~mL}$ fresh growth medium (RPMI $1640+$ $10 \% \mathrm{FBS}$ ), and incubated for $30 \mathrm{~min}$ in $5 \% \mathrm{CO}_{2}$ at $37^{\circ} \mathrm{C}$. Rhodamine 123 (Rho-123, final concentration: $1.0 \mu \mathrm{mol} / \mathrm{L}$ ) was added to the cells for incubating another $1 \mathrm{~h}$ in the same solution. The medium containing Rho-123 was removed and the cells were washed with cold phosphate buffered saline (PBS, pH 7.4) three times for flow analysis. Fluorescence of Rho-123 was collected through a 530/30 nm bandpass on a FACSCalibur flow cytometer. After gating for live cells, 30000 cells were recorded for each sample and processed by Cell Quest software.

\subsection{Chemosensitivity to doxorubicin}

MCF7/ADR cells $\left(8 \times 10^{4} /\right.$ well) were plated in 24 -well plates for siRNA interference. After transfection for $72 \mathrm{~h}$, the media was replaced with fresh supplemented RPMI 1640 (500 $\mu \mathrm{L})$ containing doxorubicin $(263 \mu \mathrm{mol} / \mathrm{L})$. After incubation at $37^{\circ} \mathrm{C}$ in $5 \% \mathrm{CO}_{2}$ for $24 \mathrm{~h}$, the medium was poured out and the cells were then treated with $500 \mu \mathrm{L}$ of MTT (3 $\mathrm{mg} / \mathrm{mL}$ in PBS) and incubated for another $4 \mathrm{~h}$. Then the medium was removed, the cells were lysed by adding 600 $\mu \mathrm{L}$ of DMSO, and the absorbance of the purple formazan was recorded at $520 \mathrm{~nm}$ using a BIO-TEK plate reader.

\section{Results and discussion}

Based on its nucleic acid delivery vector capabilities, PFP was specifically used for drug resistance regulation through RNA interference. Our previous results demonstrate that the PFP exhibits lower cytotoxicity on Dox-resistant human breast adenocarcinoma (MCF7/ADR) cells. Although the cell viability decreases after $24 \mathrm{~h}$ incubation upon increasing concentration of PFP $(0-10 \mu \mathrm{mol} / \mathrm{L})$, the viability is still larger than $70 \%$. To study the PFP for siRNA delivery and transfection, the siRNA that can down-regulate Dox resistance in MCF7 cells was used in our experiment. Firstly, we examined whether PFP could protect siRNA against enzyme degradation. As shown in Figure 1, similar results were obtained as with pDNA, in that siRNA forms tight complexes with PFP to resist enzyme degradation. The dynamic light scattering (DLS) and zeta potential experiments show that the average hydrodynamic diameter of the $\mathrm{PFP} / \mathrm{siRNA}$ complex is $865 \mathrm{~nm}$ and that the $\zeta$ potential is $+18 \mathrm{mV}$, which are favorable for delivery of siRNA into the cells.

$\beta$-actin is a globular protein found in all eukaryotic cells, which is always used as an internal control for gene express [25]. cDNA is a complementary DNA of mRNA from reverse transcriptional mRNA template, which can reflect the quantitative level of mRNA. As shown in Figure 2, after transfection, the level of MDRI mRNA has been significantly reduced by using PFP as the vector in comparison to $\beta$-actin control. This result suggests that PFP can function as an efficient siRNA delivery vehicle for gene based drug resistance regulation. It is noted that there is no band attributed to MDRI and $\beta$-actin appearing on the agarose gel when using Lipo as the vector, which indicates that the toxicity of Lipo is limited for siRNA interference to MCF7/ ADR cells.

The overexpression of MDRl gene and its product, $\mathrm{P}$ glycoprotein (P-gp), is a particularly significant mechanism for drug resistance. P-gp is a $170 \mathrm{kDa}$ transmembrane phosphoglycoprotein that acts as an energy-dependent drug efflux pump capable of extruding various chemotherapeutic drugs such as doxorubicin (Dox) from cell cytoplasm to outside of plasma membrane [26], leading to reduced intracellular effective drug concentration and augmenting cell

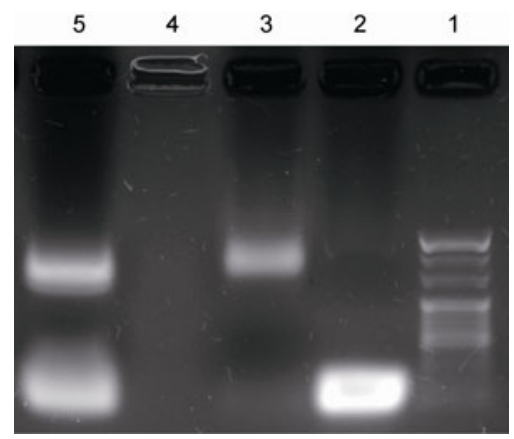

Figure 1 Protection of siRNA from nuclease degradation. Lane 1: $20 \mathrm{bp}$ marker; lane 2: naked siRNA; lane 3: naked siRNA with FBS; lane 4: PFP/ siRNA; lane 5: PFP/siRNA digested with FBS.

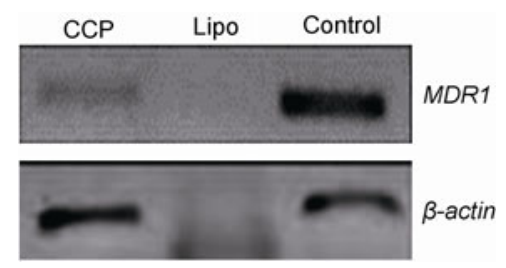

Figure 2 The gel result of cDNA from MDR1 mRNA by siRNA interference with PFP and Lipo 2000 as transfection agents. $\beta$-actin was used as an internal control. 

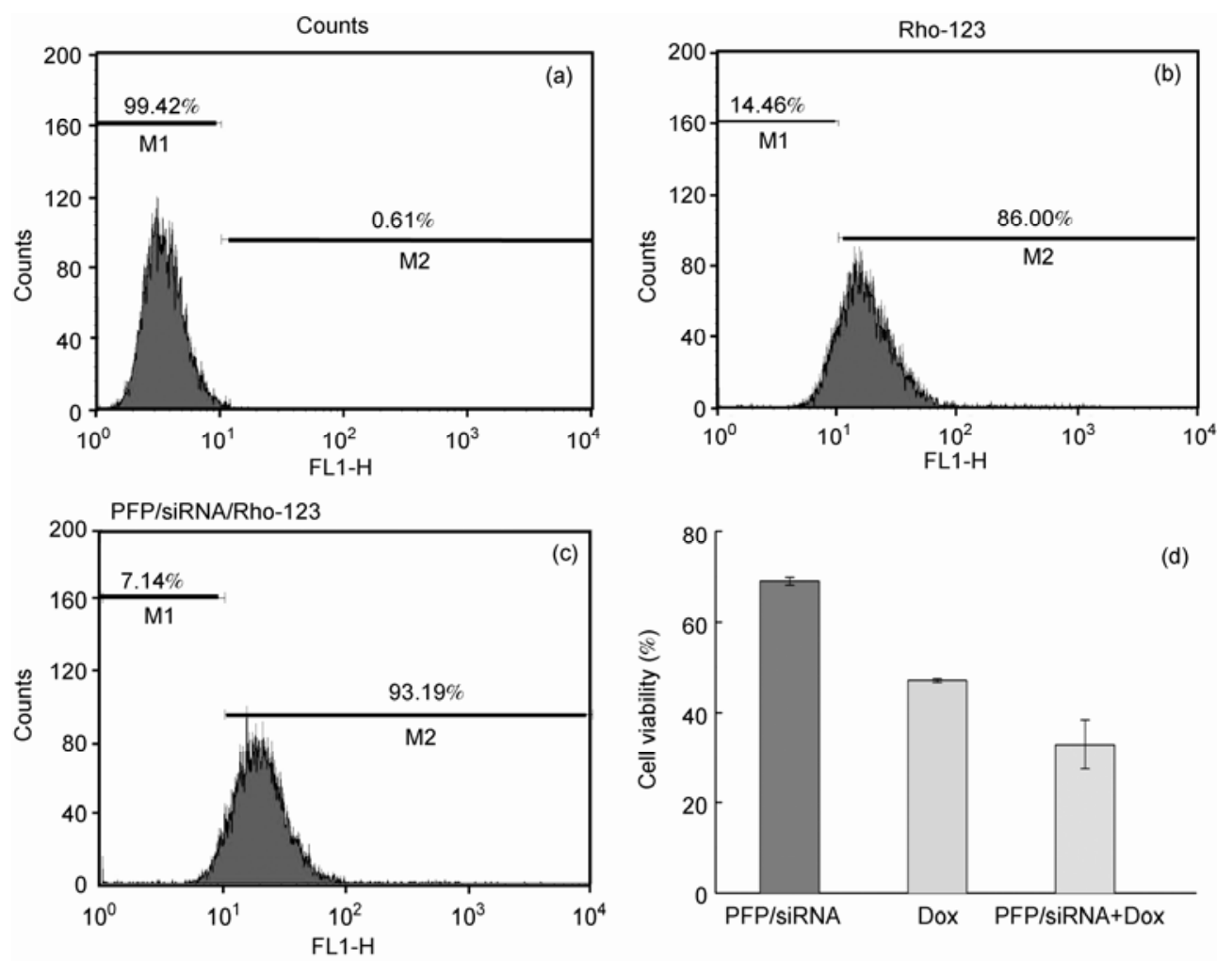

Figure 3 (a)-(c) Rho-123 efflux assays for evaluating the activity of P-gp. FACS histograms of MCF7/ADR cells without any treatment (control) or treated with $1 \mu \mathrm{mol} / \mathrm{L}$ Rho-123 for $1 \mathrm{~h}$. (d) MCF7/ADR cell viability in the presence of Dox before and after treatment with PFP/siRNA, and that of treatment only with PFP/siRNA as control.

survival against anticancer drugs. Rhodamine 123 (Rho123), a fluorescent substrate of P-gp, has been widely chosen to evaluate the drug efflux ability of P-gp [27]. Figure 3(a)-(c) shows flow cytometry histograms of gated living cells with distribution of Rho-123 fluorescence, in which marker M1 was placed around the peak of cell autofluorescence (MCF7/ADR cells without Rho-123) as control, and marker M2 was placed to the right of M1 to designate the percentages of cells with the fluorescence of Rho-123. In the absence of siRNA treatment, there was some Rho-123 accumulating in cells with M2 of $86.00 \%$. After treatment with PFP/siRNA, an increase in Rho-123 accumulation was observed with an M2 value of $93.19 \%$. The enhancement of chemosensitivity to Dox was expressed as the decrease of the survival rate after incubation with Dox of siRNA-treated cells compared with siRNA-untreated control cells. As shown in Figure 3(d), after treatment with PFP/siRNA, the cell viability was decreased to $33 \%$ in the presence of Dox comparing to that without treatment with PFP/siRNA (47\%). All these results demonstrate that PFP is good siRNA transfection agent, and can efficiently achieve the reversal of drug resistance and enhance the drug sensitivity.

\section{Conclusions}

In summary, the cationic dendritic conjugated polymer PFP can act as efficient siRNA delivery vector by facilitating the nucleic acid binding, encapsulation and efficient cellular uptake. PFP can effectively protect siRNA against nuclease degradation, which is necessary for gene carriers. PFP can be used for multidrug resistance gene-targeted siRNA delivery in doxorubicin (Dox)-resistant human breast cancer cells (MCF7) cells. As a siRNA transfection agent, PFP can efficiently achieve the reversal of drug resistance and enhance the drug sensitivity. To the best of our knowledge, this is the first reported conjugated polymer that can be employed for gene-based drug resistance regulation. These new features and capabilities represent an innovative step toward synthetic polycationic vectors for therapeutic applications.

This work was supported by the National Natural Science Foundation of China (21203213, 21033010, 21021091).

1 Kawasaki K, Watanabe M, Sakaguchi M, et al. REIC/Dkk-3 overexpression downregulates P-glycoprotein in multidrug-resistant MCF7/ ADR cells and induces apoptosis in breast cancer. Cancer Gene Therapy, 2009, 16: 65-72

2 Ling V. Multidrug resistance and P-glycoprotein expression. Ann NY Acad Sci, 1987, 507: 7-8

3 Ueda K, Cardarelli C, Gottesman M M, et al. Expression of a full-length cDNA for the human "MDR1" gene confers resistance to colchicine, doxorubicin, and vinblastine. Proc Natl Acad Sci USA, 1987, 84: 3004-3008 
4 Sonneveld P, Durie B G, Lokhorst H M, et al. Modulation of multidrug-resistant multiple myeloma by cyclosporin. Lancet, 1992, 340: 255-259

5 Baumert C, Hilgeroth A. Recent advances in the development of P-gp inhibitors. Anti-Cancer Agents Med Chem, 2009, 9: 415-436

6 Que-Gewirth N S, Sullenger B A. Gene therapy progress and prospects: RNA aptamers. Gene Therapy, 2007, 14: 283-291

7 Langer R, Tirrell D A. Designing materials for biology and medicine. Nature, 2004, 428: 487-492

8 MacDiarmid J A, Amaro-Mugridge N B, Madrid-Weiss J, et al. Sequential treatment of drug-resistant tumors with targeted minicells containing siRNA or a cytotoxic drug. Nat Biotechnol, 2009, 27: 643-651

9 Kim D H, Rossi J J. Strategies for silencing human disease using RNA interference. Nat Rev Gene, 2007, 8: 173-184

10 Gary D J, Puri N, Won Y Y. Polymer-based siRNA delivery: Perspectives on the fundamental and phenomenological distinctions from polymer-based DNA delivery. J Controlled Release, 2007, 121: 64-73

11 Check E. Gene therapy put on hold as third child develops cancer. Nature, 2005, 433: 561

12 Jere D, Xu C X, Arote R, et al. Poly(beta- amino ester) as a carrier for si/shRNA delivery in lung cancer cells. Biomaterials, 2008, 29: 2535-2547

13 Duan X, Liu L, Feng F, et al. cationic conjugated polymers for optical detection of DNA methylation lesions and single nucleotide polymorphisms. Acc Chem Res, 2010, 43: 260-270

14 Feng X, Liu L, Wang S, et al. Water-soluble fluorescent conjugated polymers and their interactions with biomacromolecules for sensitive biosensors. Chem Soc Rev, 2010, 39: 2411-2419

15 Thomas S W, Joly G D, Swager T M. Chemical sensors based on amplifying fluorescent conjugated polymers. Chem Rev, 2007, 107: 1339-1386
16 Pecher J, Mecking S. Nanoparticles of conjugated polymers. Chem Rev, 2010, 110: 6260-6279

17 Silva A T, Nguyen A, Ye C, et al. Conjugated polymer nanoparticles for effective siRNA delivery to tobacco BY-2 protoplasts. BMC Plant Biol, 2010, 10: 291

18 Ho H A, Najari A, Leclerc M. Optical detection of DNA and proteins with cationic polythiophenes. Acc Chem Res, 2008, 41: 168-178

19 Zhu C L, Liu L B, Yang Q, et al. Water-soluble conjugated polymers for imaging diagnosis and therapy. Chem Rev, 2012, 112: 4687-4735

20 Wen Q S, Tang H W, Yang G M, et al. Synthesis and characterization of oligofluorene nanoparticles for cell imaging, Acta Chim Sinica, 2012, 70: 2137-2143

21 Tang Z Y, Cheng Y Q, Du Q. Integration of rolling circle amplification and cationic conjugated polymer for homogeneous detection of single nucleotide polymorphisms. Chin Sci Bull, 2011, 56: 3247-3252

22 An L L, Liu L B, Wang S. Cationic conjugated polymers for homogeneous and sensitive fluorescence detection of hyaluronidase. Sci China Chem, 2009, 52: 827-832

23 Feng X L, Lv F T, Liu L, et al. A highly emissive conjugated polyelectrolyte vector for gene delivery and transfection. Adv Mater, 2012, 24: 5428-5432

24 Chen C, Clark D, Ueda K, et al. Genomic organization of the human multidrug resistance (MDR1) gene and origin of P-glycoproteins. J Biol Chem, 1990, 265: 506-514

25 Carlyle W C, Toher C A, Vandervelde J R, et al. Changes in betaactin mRNA expression in remodeling canine myocardium. J Mol Cell Cardiol, 1996, 28: 53-63

26 Ford J M, Hait W N. Pharmacology of drugs that alter multidrug resistance in cancer. Pharmacol Rev, 1990, 42: 155-199

27 Altenberg G A, Vanoye C G, Horton J K, et al. Unidirectional fluxes of rhodamine 123 in multidrug-resistant cells: Evidence against direct drug extrusion from the plasma membrane. Proc Natl Acad Sci USA, 1994, 91: 4654-4657

Open Access This article is distributed under the terms of the Creative Commons Attribution License which permits any use, distribution, and reproduction in any medium, provided the original author(s) and source are credited. 